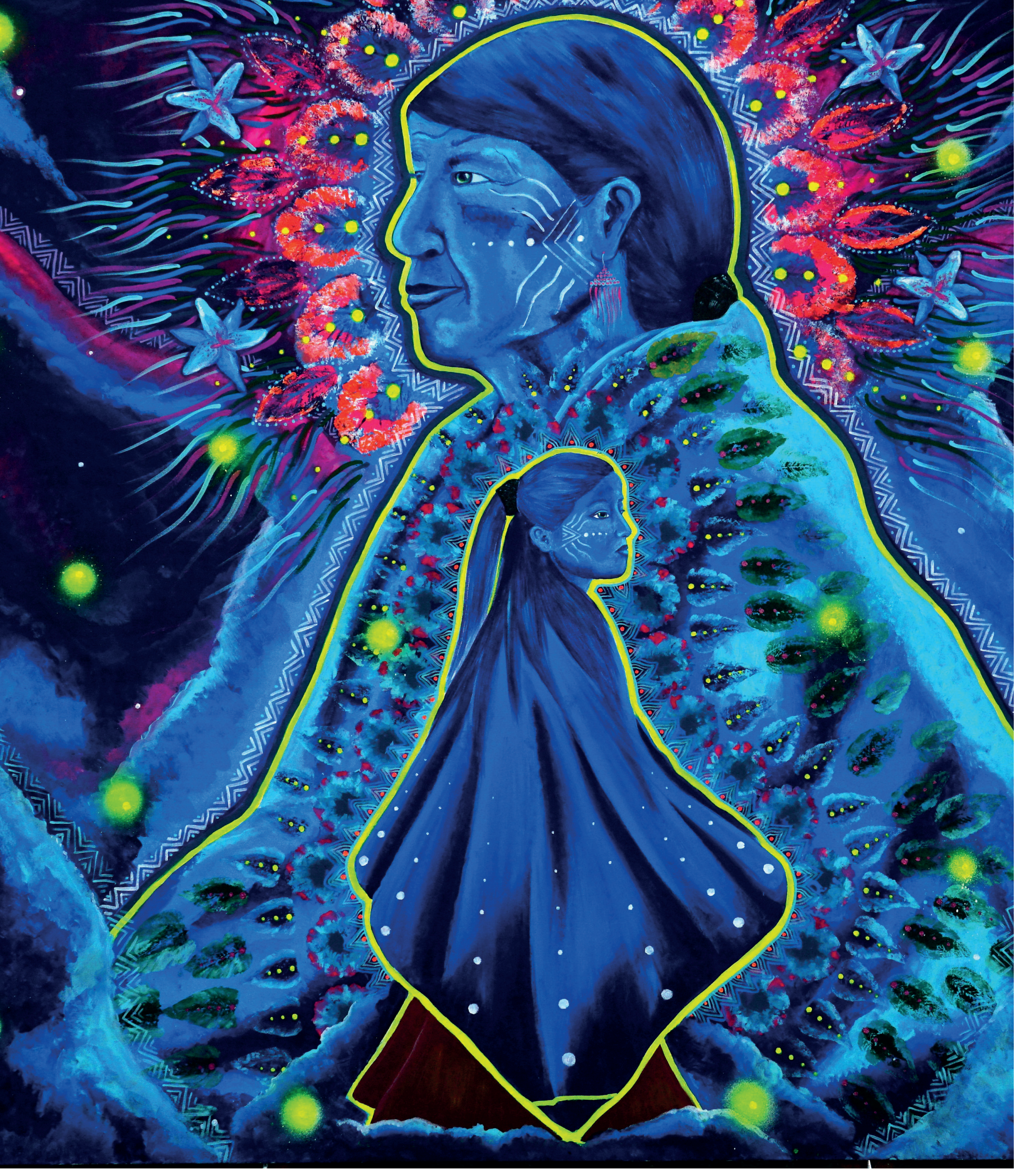




\section{Chisua: tejidos de voces maestras y saberes de maestros}

Volumen $7 \mathrm{~N} .049$ julio-diciembre de 2020

ISSN: 0122-4328

ISSN-E: 2619-6069 pp. 61-72
Chisua: Weaving

Teachers' Voices and

Teachers' Knowledge

\author{
Chisua: tecelagem \\ das vozes dos \\ professores e dos \\ conhecimentos dos \\ professores
}

Tadiana Guadalupe Escorcia Romero*

Ana Brizet Ramírez Cabanzo**

Karen Martínez ${ }^{* * *}$

Edith Constanza Negrete Soler ${ }^{* * *}$

Roberto Esteban Hoyos Martínez ${ }^{* * * * *}$

Lina Piedad Gómez ${ }^{* * * * *}$

Cesar Damián Castro Páez $z^{* * * * * *}$

Fecha de recepción: 30-04-20

Fecha de aprobación: 19-11-20

\section{PARA CITAR ESTE ARTÍCULO}

Escorcia, T., Ramírez, A., Martínez, K., Negrete, E., Hoyos, R., Piedad, L. y Castro, C. (2020). Chisua: tejidos de voces maestras y saberes de maestros. Nodos y Nudos, 7(49). https:// doi.org/10.17227/nyn.vol7.num49-11661
* Magister en estudios en Infancias de la Universidad Pedagógica Nacional y Universidad de Antioquia Licenciatura en Educación Infantil, Universidad El Bosque. IED José Asunción Silva. Correo: naomitadi@gmail.com Orcid: https://orcid.org/0000-0001-5933-6797

* Doctora en Educación de la Universidad Pedagógica Nacional. Licenciatura en Educación Infantil, Universidad Distrital Francisco José de Caldas. Correo: anabrizet@gmail.com Orcid: https://orcid.org/0000-0001-7240-6788

** Magíster en Comunicación-educación Universidad Distrital Francisco José de Caldas. IED La Aurora. Correo: kamg90@ gmail.com Orcid: https://orcid.org/0000-0002-6074-7996

*** Magíster en enseñanza de las ciencias exactas y naturales, Universidad Nacional de Colombia. INEM Francisco de Paula Santander. Correo: negretesoler@gmail.com Orcid: https:// orcid.org/0000-0001-5419-2077

**** Magister en Educación y Desarrollo Humano, CindeUniversidad de Manizales. Institución Educativa Vida para todos. Correo: estehoyos78@gmail.com Orcid: https://orcid. org/0000-0002-6853-3968

***** Magister en Educación Universidad Santo Tomás. . E. Silvino Rodríguez. Correo: lipigosa@gmail.com Orcid: https://orcid. org/0000-0001-9763-3741

****** Estudiante Licenciatura en Educación Infantil uPTC. Correo: cesar.castro02@uptc.edu.co Orcid: https://orcid. org/0000-0003-1155-6453 


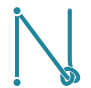

Volumen 7 N. ${ }^{\circ} 49$ julio-diciembre de 2020 ISSN: 0122-4328

ISSN-E: 2619-6069 pp. 61-72

\section{RESUMEN}

Este tejido de letras, afectos, saberes e historias muestra los hilos que han entramado los sentidos de vida de la Red Chisua, retomando el vocablo muisca que significa "mochila". En ese cúmulo de experiencias, la participación en los encuentros iberoamericanos y en otros eventos ha venido trenzando el colectivo. Este artículo de reflexión muestra el acontecimiento de ser red para los maestros en formación y en ejercicio; cómo las tramas que alli se tejen, se bifurcan en otros territorios y con otras redes; $y$, las dinámicas de la construcción epistémica y la contribución en la consolidación de la política pública educativa. Inicialmente se presenta el origen de la red y su modelado en el tiempo. Seguidamente se explica cómo el tejido demarca nudos y desenredos, y los lenguajes que lo han hecho posible. Finalmente, se expone cómo el ímpetu de la colectividad inspira a cre-ser como maestras y maestros "de a pie" que trabajan por escuelas constructoras de paz y de puertas abiertas..

Palabras clave: tejido; producción de subjetividades; saber pedagógico; redes de maestros; narrativas; saberes; investigación; innovación educativa y pedagógica

\section{ABSTRACT}

This weaving of letters, affections, knowledge, and stories shows the threads that have woven the meanings of life of the Chisua Network, taking up the Muisca word meaning "backpack". In this accumulation of experiences, participating in the lbero-American meetings and other events has been weaving the collective. This reflective article shows the experience of being a network for teachers in training and in practice; how the plots that are woven in there are bifurcated into other territories and to other networks; and the dynamics of epistemic construction and the contribution for consolidating public educational policy. Initially, the origin of the network and its modeling over time are presented. Next, it is explained how the weaving demarcates knots and disentanglements, and the languages that made it possible. Finally, it is shown how the impetus of the collective inspires us to grow as "ordinary" teachers who work for schools that build peace and open doors.

Keywords: weaving; production of subjectivities; pedagogical knowledge; teachers' networks; narratives; knowledge; research; educational and pedagogical innovation

\section{RESUMO}

Esta tecelagem de letras, afetos, conhecimentos e histórias mostra os fios que teceram os significados da vida da Rede Chisua, retomando a palavra muisca que significa "mochila". Neste acúmulo de experiências, a participação em encontros ibero-americanos e outros eventos vem tecendo o coletivo. Este artigo de reflexão mostra o evento de ser uma rede de professores em treinamento e na prática; como as parcelas que são tecidas ali são bifurcadas em outros territórios e com outras redes; e a dinâmica da construção epistêmica e a contribuição para a consolidação da política de educação pública. Inicialmente, é apresentada a origem da rede e sua modelagem ao longo do tempo. Em seguida, explica como a trama nos demarca e desencontros, e os idiomas que tornaram isso possivel. Finalmente, mostra como o impulso do coletivo nos inspira a acreditar como professores "comuns" que trabalham para escolas que constroem a paz e abrem portas.

Palavras-chave: tecelagem; produção de subjetividades; conhecimento pedagógico; redes de professores; narrativas; conhecimentos; pesquisa; inovação educacional e pedagógica 
Cuenta la tejedora muisca el don de sus abuelos al sacar de unas hojas carnosas y largas el fique para tejer, ahora sigue su legado con lana, como cuando teje la mochila que simboliza el inicio de la vida, la placenta y la saga el cordón umbilical.

(Chubasuque, 2017, Citado POR HERNÁNDEZ, 2017).

A la mochila le llaman "chisua", el mismo nombre que lleva nuestra red de maestros y maestras

investigadoras y a partir del cual se teje este texto de construcciones pedagógicas, huellas y saberes.

\section{Hilando en un mismo sentir}

Uno de los hilos de esta mochila inicia hacia el año 2000 en la localidad de Usme, donde nace, desde las necesidades de las infancias y familias, una propuesta pedagógica e investigativa denominada "Expedición escolar C", como una "construcción conjunta de espacios diferentes en la pedagogía para todos aquellos que son vulnerados en su mismidad" (Ramírez et ál., 2006, p. 65). Esta apuesta afirma en un trío de maestras el camino para hacer de su escuela un escenario de diálogo, que retoma factores de riesgo para transformarlos en factores de protección, de transformación pedagógica y de construcción de saber. Se gesta también como un motor que inspira a comprender que más allá de contenidos, lo que cobra importancia es la constitución de un sujeto que se reconoce, reconstruye y encuentra en sus debilidades, razones para resistir y cre-ser. Esa expedición permitió pensar y articular:

el mundo infantil y juvenil con el escolar desde el diálogo con la familia, amigos, barrio y escuela como un mismo entorno, para poder comprender sus realidades, desde la transformación de aprendizajes, que develan otras maneras de querer vivir y estar en uno y otro espacio, pero particularmente, aquel que visibiliza las voces de quienes han sido oprimidos. (Ramírez et ál., 2006, p. 72)

De esta manera, se afianzan las primeras puntadas de esta chisua que siente la necesidad de seguir visibilizando las apuestas comunitarias nacidas en la IED Monteblanco, para que en otros escenarios educativos también pudiera replicarse. Y ello, como lo diría un expedicionario del 2004, porque "aquí todos somos especiales, aunque seamos de un tamaño, forma o color distinto; cada uno marcha a su propio ritmo y en esta expedición todos llegamos a la meta" (Expedicionario 2004, citado por Ramírez et ál., 2006, p. 70).

Al aprender a hacer investigación, el tejido en red empezó a gestar, en formas, motivos y sentidos, una mochila que contiene y se extiende hacia otros escenarios. Un dia de camino por la ciudad, nos topamos con un lugar donde funcionaba la Red CEE (Red de Cualificación de Educadores en Ejercicio de la Universidad Pedagógica Nacional), que abriria sus brazos para contener nuestras preguntas, ilusiones, pero sobre todo la necesidad de seguir siendo maestras por las voces de sus comunidades. En el acogimiento de la Red CEE, sistematizar las construcciones de ese camino expedicionario se convierte en el pórtico para poner en escena estos discursos, haciéndonos partícipes como ponentes en eventos locales y distritales', y coordinadoras de mesas de trabajo donde las experiencias en torno a las infancias serían un puente de diálogo epistémico con otros actores.

Por todo lo que había significado durante esos años ser maestras también desde otros espacios para fortalecer el andar pedagógico, somos invitadas a participar en el Encuentro lberoamericano de Redes de Maestros que hacen Investigación en el Aula, esta vez para afirmar las puntadas de una escuela constructora de país, en Lajeado, Brasil. Tal propósito inundó nuestros corazones de ilusiones, aunque al mismo tiempo de miedos e imposibilidades, pues lo económico se anteponía como obstáculo; sin embargo, un lema que fue vida para nosotras -"todas para una y una para todas"- nos llevó a tejer esta vez internacionalmente. Sí, con préstamos, pero con la fuerza permanente de nuestros niños, niñas y sus familias, y el orgullo de nuestro rector, fue posible viajar hasta allí.

\footnotetext{
1 III Encuentro de docentes que lideran y participan en proyectos educativos en niñez (2005); Encuentro distrital de investigaciones y experiencias en educación y pedagogía (IDEP, 2007); I Encuentro de experiencias significativas institucionales para la conformación de colectivos de maestros de la localidad quinta, entre otros.
} 
Es además desde esa experiencia que te hermana con maestros de otras latitudes en un mismo sentir, que ser red empieza a cobrar sentido, porque con otros, los procesos tienen mayor potencia. De acuerdo con Escorcia, en esta movilización es latente

una constante motivación por hacer de su comunidad educativa un protagonista para dar respuestas a los múltiples interrogantes que plantea la educación; ser maestro hoy implica tejer junto a otros, pues los constructos pedagógicos fundamentan sus bases junto a sus experiencias, que se han validado con el devenir de los años. (2019, p. 158)

Alli se nutre el andar, porque se hace indispensable contar con palabras, textos y mayores vivencias las múltiples posibilidades que la escuela te otorga para ser un maestro "sujeto de saber, sujeto de deseo y sujeto de acción política" (Martínez, 2005, p. 4). La Red CEE seguiria en ese entonces afirmando puntadas para seguir tejiendo estos hilos, que llevaron a iniciar en la IED un colectivo en el que todas las maestras de preescolar y básica primaria de tres sedes desarrollaríamos el proyecto "Usme, mi nido de amor" para recuperar la memoria de la localidad. Todas las áreas cruzan saberes, y como resultado se consolidó un libro en el que cada maestra escribió un artículo; niños y niñas de cada grado hicieron el suyo desde sus grafías e imágenes. Ello daría paso a participar en otro de los Iberos, esta vez en Venezuela, donde se llega para evocar que ser institución y localidad, es ser país:

"Ustedes no hicieron Usme, hicieron Colombia" [...] en estos momentos es cuando el aula se hace universo y trasciende las paredes tocando la piel de otros paises, es la diariedad del aula un espacio para cre-ser como seres humanos y maestras, donde no importa la dificultad, los obstáculos, ni quienes no creen en la transformación y el compromiso de la escuela, ya que el abrazo y el ánimo de cada mosquetero latinoamericano es la voz de esperanza por nuestros estudiantes. (Escorcia et ál, 2008, p. 105)

\section{De puntadas - una a}

\section{una- para ser mochila}

En un café del centro de la ciudad, tejiendo palabras y ensueños, nos empieza a contener el anhelo de tejer nuestra mochila pedagógica, y así con seis integrantes nace la Red Chisua. Desde 2007, como vasija de encuentros que recupera relatos y pensamientos, se comprende que la investigación desde distintos actores maestros(as) y contextos es un aliado del camino que va enlazando al colectivo. Alli se forjaría una de las enseñanzas de ser red, que hay que "ser con el otro, no desde la competencia que anula y desconoce, sino desde el diálogo y el encuentro, en el que las ideas y prácticas nutren y afirman la pedagogía... tal como lo hiciera walekeru² al tejer bajo la luna, para dejar su herencia a los wayúu" (Escorcia, 2019, p. 159).

En efecto, cuando un(a) maestro(a) decide entrelazarse con otros, se ve inmerso en un tejido continuo para hacer de su territorio escolar un libro para ser escrito; entre párrafos y borradores, así como guarda la memoria de las múltiples construcciones pedagógicas y los hallazgos que demarcan una comunidad empoderada, da voz a maestros(as) cuyas experiencias hacen visible una educación que dignifica a las familias y les otorga un lugar en la escuela donde se constituyen en sabedores del proceso. Así

la red se fortalece como espacio de participación democrática, pero también como uno para la construcción de conocimiento pedagógico y de posición crítica basado en el diálogo intercultural de saberes y de investigación politicamente comprometida [...] hacia la transformación sociocultural en nuestro continente. (Segura et ál., 2006, p. 10)

Sin embargo, es probable que en ciertos momentos los hilos se enreden ante las resistencias cuando se transforma la escuela que rompe las verticalidades donde se homogeniza, desconociendo la diversidad de etnias e historias de vida de quienes hacen el aula, lo que sin duda tiende a desalentar. Justo allí, la red te contiene, al recuperar tu voz y escritura, para fortalecer saberes pedagógicos que desde lo colectivo legitiman y proyectan el quehacer, la institución y la misma academia. A decir de Escorcia, "tiempos, retos y contextos van mostrando un devenir de situaciones que suponen una constante preparación; no desde lo meramente teórico, sino desde el rescate de

2 "Araña" en wayuunaiki, origen del tejido en la etnia wayúu. 
la experiencia, preguntas y desaciertos que cobijan a quien enseña" (2019, p. 159), para incidir en la formación y cualificación profesional.

Ese devenir que se anuncia es el camino para exponer-se a otros y a sí mismo. Exponerse es traducir la experiencia con múltiples discursos y saberes; es situar al (a la) maestro(a) como un intelectual de la pedagogía "de a pie", que, con imaginación, tesón y experticia, transforma las inequidades que forman parte de la sociedad desde la esperanza recuperada en los entornos educativos y donde somos aprendices del mundo de la vida (Ramírez-Cabanzo, 2018). En otras palabras, es un "lugar en el que salir del aula es aprender para poder enseñar sin desconocer a quien la vive, para darle cuerpo y elementos que posibiliten traducirla al texto escrito, siendo productor de saber, de textos, de pedagogía" (Escorcia, 2019, p. 159). Hoy más que nunca la red genera oportunidades para poner en juego una episteme dinámica frente a los debates educativos y este compromiso, se imprime al ser parte de un tejido que revitaliza la esperanza de los territorios escolares que le apuestan a la paz.

\section{Producción epistémica en clave de red}

Aparecen los ruidos pedagógicos en el diario vivir, que nombrados desde la sociología del medio ambiente por Artemio Baigorri (1995) se entienden como un efluente de la propia vida social, es decir, una salida en el aparente orden del sistema humano donde interactuamos los (las) maestros(as). Estas perturbaciones, dependen de las percepciones subjetivas que se reconocen tanto en el plano individual como en el de las interacciones; la movilización que se enuncia es autopoiesis, o por decirlo de otro modo, la ecología humana en la pedagogía. Frente a esas perturbaciones, ser red, como fruto del encuentro entre maestros(as) y educadores(as) de diferentes instituciones, niveles, disciplinas y regiones, ha conllevado a fundamentar algunas nociones que cohesionan la intelectualidad del colectivo: el (la) maestro(a) como intelectual de la pedagogía, la sistematización en clave de cartografía y las pedagogías colectivas para la paz.
Los (las) maestros(as) como intelectuales de la pedagogía

La Red Chisua se ha propuesto intentar topografiar lo que nos constituye como maestros(as), siendo la investigación y la innovación, las banderas que dan norte a aquellas producciones de saber pedagógico que se fraguan en la heterogeneidad de experiencias prácticas que implican "aprender una mentalidad como una posturalidad", en palabras de Dewey (Ramírez-Cabanzo, 2018, p. 15).

Cuando asumimos ejercicios intencionados de reflexividad alrededor de lo que hacemos, manifestamos el lugar de la indagación sistemática que nos moviliza en el territorio como intelectuales de la pedagogía, sujetos "de a pie". A decir de Ramírez-Cabanzo (2018), la incertidumbre y la actitud de problematización de las relaciones con los adentros y afueras del acontecer formativo en diálogo con aristas comunicativas, culturales, sociológicas, políticas, éticas, tecnológicas y estéticas, son las que nos habilitan y empoderan para pensar con autonomía; una legitimidad que nos estamos ganando a pulso y que nos permite revitalizar y continuar con los propósitos del Movimiento Pedagógico iniciado en los años 1980, caminando y fortaleciendo las luchas por el reconocimiento de la condición docente.

Lo anterior nos insta a resistirnos a esa condición de minoridad tan acostumbrada que titula a los (las) educadores(as) como incapaces de pensar por si mismos y, por tanto, de investigar. De acuerdo con Martínez y Unda, el tejido en red permite "el despliegue de nuevas experiencias que nos potencien en términos de generación de un espíritu libre, de una vinculación más estrecha con el pensar como ejercicio de la imaginación" (1995, p. 5), y ello se refleja en la motivación para hacer emerger iniciativas, escrituras, eventos y múltiples participaciones que se proponen como parte del crecimiento del estar entre.

Cuando maestros(as) en red toman distancia crítica de las políticas neoliberales y los modelos hegemónicos que imperan en los sistemas educativos cada vez más instrumentalizados, se sitúan en la complejidad sociocultural de los contextos que habitan $y_{\text {, }}$ 
desde alli, crean procesos educativos más democráticos que le apuntan a la formación de ciudadanías. Tal como lo plantean Martínez y Unda (1995), el maestro se asume como intelectual de la pedagogía cuando articula a lo que hace y al acto del pensar lo que hace, los debates del saber y la cultura que le son propios. El compromiso ético con las infancias, las juventudes y las comunidades deviene en hacer de la problematización de la cotidianidad, una dimensión constituyente de su quehacer y que le titula como un maestro de a pie.

Otro de los sentidos ético-políticos a los que apelamos como maestros(as) intelectuales de la pedagogía es el reconocimiento de ser sujetos productores, mediadores y traductores constituyentes de la cultura con las comunidades, con las cuales movilizamos el espíritu de cambio social en la cotidianidad. Situarlas como epicentro del acontecimiento formativo es lo que nos permite reflexionar sobre nuestra práctica; es el oficio de enseñar que reclama su reflexión permanente como dimensión constitutiva del saber del (de la) maestro(a) para hacerlo nominable y descriptible (Zuluaga, 1999; Tezanos, 2016) en la intersubjetividad.

A partir de los Encuentros Iberoamericanos de Colectivos y Redes de Maestros, esa intelectualidad se afianza como un acto político, que desdibuja la imagen del maestro como sujeto mínimo, al "agenciar y construir saberes y sujetos autónomos, supera la pasividad y la condición de espectadores" que "interviene en las decisiones sobre lo educativo y sobre la política educativa" (Martínez, 2005, p. 6). La responsabilidad con el saber del otro y la valía de su experiencia es otro de los pilares éticos de la red, pues su producción no es ajena al mundo de la vida; todas las letras que se construyen pensando la práctica van entretejiendo afectos, amores y desamores, lágrimas y alegrías; allí la escritura se convierte en una contención del espíritu para volver a nacer cada día como un(a) educador(a) inquieto(a) que se dispone a la colegiatura del saber compartido.

\section{La sistematización en clave de cartografía}

En los debates hemos comprendido que es la experiencia la que soporta que la sistematización sea la fuente para hacer emerger distintos niveles de reflexividad, y por ello nos alejamos de pensarla como documentación de meros datos e informaciones. De acuerdo con Ramírez-Cabanzo (2016), cuando se asume la sistematización en clave de cartografía pedagógica, las experiencias educativas son topografiadas, por tanto, susceptibles de levantar sus actores, sentidos, territorios y fronteras, en el conjunto de sus dinámicas y complejidades.

Vista así, la sistematización implica situar la cotidianidad educativa en notación de praxis para poder comprender cuáles y cómo son los procesos de educabilidad y enseñabilidad que alli se agencian. Serán entonces las dimensiones del contexto, las subjetividades, el currículo, la práctica pedagógica, los procesos académicos y convivenciales, los aprendizajes, las formas de enseñanza y el mundo de la vida, los que mueven a posicionar el acontecimiento formativo y los que dan su sentido. El registro y análisis desde la cartografía lleva a la deconstrucción de los significados e interpretaciones propias del rastreo sistemático y diferencial de los sistemas simbólicos de las experiencias.

Epistemológicamente, la sistematización ha permitido ir tras la huella de sí del quehacer de maestros(as), desde la indagación reflexiva y participativa de las realidades educativas, así como de los imaginarios de los sujetos que la hacen posible. En este sentido, la cartografía pedagógica convierte la realidad educativa en un contexto de aprendizaje de la propia práctica en el que se reconocen cómo los entornos familiares, culturales, ambientales, económicos, comunicativos, estéticos y geográficos, se entraman en los trayectos de saber que colectivizan el espacio escolar y comunitario. Varios de los (las) maestros(as) de la Red Chisua, a partir de esta metodología se enfrentaron por primera vez a la lectura de sus experiencias, dado que no las habían documentado y, por tanto, sistematizado. 
Para ello, la Red hacia el año 2015 se dio a la tarea de consolidar la siguiente rejilla para poner en diálogo la cotidianidad de la experiencia a partir de su problematización.

Figura 1. Descriptores para cartografiar las experiencias pedagógicas

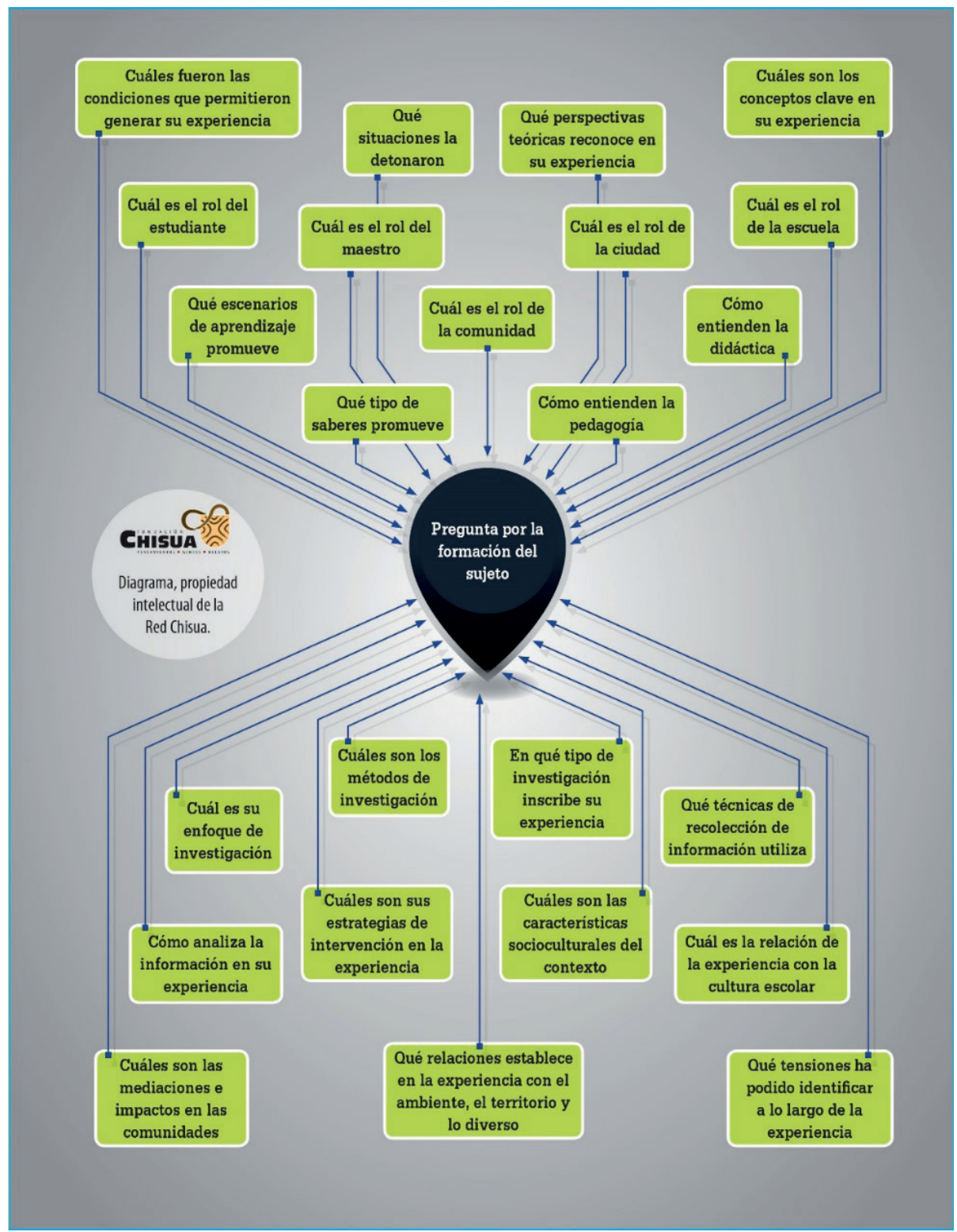

Fuente: Red Chisua.

Los descriptores planteados en clave de cartografía pedagógica han conllevado a investigar la práctica en torno a la pregunta formativa por el sujeto, a través de relatos, árbol de problemas, rejillas de sistematización, entre otros elementos de seguimiento y mapeo gráfico, textual y mental. Este ejercicio ha dado lugar no solo a lecturas situadas que implican identificar un horizonte de problematización en cada experiencia; también, a formas de reconocimiento de la valía de los procesos que logran maestros(as) en el día a día, pues muchos de ellos ni siquiera habian dado cuenta de la potencia que tienen en sus manos. 
En sintesis, la sistematización de las experiencias ha hecho nacer la semiótica que fundamenta la praxis, al promover una episteme que hace zoom en su práctica, es decir, una toma de distancia de su cotidianidad (Ramírez-Cabanzo, 2016) para reflexionarla y pensarse a sí mismo como sujeto maestro/a. Este sustrato además de suscitar que las experiencias sean leídas en clave de emancipación, con un sentido de criticidad, contraste y replanteamiento pedagógico, político, ético y estético, ha generado un espíritu por investigar e innovar desde apuestas colectivas, y hoy la red se afirma en soñar y producir iniciativas audiovisuales que recuperan la diversidad de las poblaciones, para construir culturas de paz por un mejor país.

\section{Pedagogías colectivas para la paz}

Como maestros(as) nos hemos propuesto descubrir el relato pedagógico que subyace a las experiencias de investigación e innovación que cada uno adelanta en sus contextos. La interlocución de estos lenguajes hoy más que nunca nos lleva a posicionar ejercicios comunes para conceptualizar un aparataje discursivo que denominamos pedagogías colectivas para la paz, las cuales recogen la polifonía de la solidaridad subjetiva desde las narrativas y la reflexión crítica ante las ecologías violentas que atraviesan de algún modo los mundos vitales de sus actores. Los trayectos de la sistematización nos permiten asumir las pedagogias colectivas para la paz como

aquellas pedagogías amparadas en políticas de la esperanza y en saberes que recogen la tradición cultural del pais, para apostarle a modos de encuentro y de convivencia más democráticos, pluralistas y dignificantes que le permiten a niños, niñas, jóvenes y familias, reconciliarse, repararse simbólicamente, construir memoria histórica, y formarse como ciudadanos, desde la acción educativa crítica, creativa y colectiva forjada en el entorno escolar, barrial, vecinal y comunitario. (Ramírez-Cabanzo, 2019)

Lo que hemos venido descubriendo es que al poner en diálogo las experiencias, van emergiendo actores, roles, tópicos de conocimiento, vínculos, estrategias, historias y relatos que se conectan entre sí al unísono de la formación plural y abierta que forja cultura de paz. La reflexión colectiva sobre la práctica nos implica en una praxis pedagógica para el reconocimiento ético y político del otro; es decir, en hacerlo emerger y dar rostro en su experiencia vital; comprendemos que, como educadores(as), nos debemos a la responsabilidad de la promoción de una ciudadanía consciente que articula los múltiples lenguajes de la cultura popular, los colectivos infantiles, juveniles, indígenas, afrodescendientes, rurales, entre otros, con la escuela, la ciudad y las organizaciones de base, para aprender a convivir en la diversidad que nos constituye, y a pensar-nos crítica e interculturalmente como sujetos.

No obstante, el encuentro en la narración y la sistematización de las experiencias son las claves que propician que el (la) maestro(a) sea un sujeto colectivo que posiciona su intelectualidad hecha praxis, como un acto sensible y epistémico desde el cual articula las realidades de país y los escenarios vitales de las comunidades como punto de partida de su quehacer. Así, los (las) educadores(as) apuestan a la creatividad social y pedagógica deliberada en cada uno de sus contextos como utopías posibles, al conjugar "discurso y acción práctica mediados por la reflexión crítica... y en tensión permanente con un proyecto de sociedad" (Martínez, 2008, p. 109); impronta que se anida en su vocación y oficio, para trabajar incansablemente por una educación más humana y solidaria que nos hermana como educadores(as).

\section{¿Qué significa "tejer en red"?}

Aunque que para muchos(as) maestros(as) la formación investigativa se circunscribe a los estudios posgraduales, el tejer en red les ha permitido encontrar la posibilidad de redescubrirse a si mismos en un proyecto con otros para compartir el desafío de aportar y construir algo inédito: la puesta en común de prácticas y pensamientos. Este desafío que supera a cada cual individualmente, en conjunto permite ser fuerza, entretejiendo aprendizajes, narrarse desde la complicidad y hacer nudos con las fortalezas; un espacio franco y diverso así se va constituyendo, al que se suman nuevas iniciativas, que requieren de la colegiatura de saberes y la proyección estratégica de cara a las realidades de entornos y territorios.

En consecuencia, trabajar en colectivo supone un proceso de construcción jalonado por objetivos que 
van más allá del actuar en solitario. Estar en red es incidir en otros - pares académicos, maestros(as) en formación, niños, niñas, adolescentes y sus comunidades- pedagógica y significativamente, y ello exige maestros(as) sensibles a los contextos de país, inquietos(as) e inconformes, apasionados(as) por leer-se en su cotidianidad, arriesgados(as) a pensar con autonomía, escribir sus memorias y compartir utopías posibles en el dialogismo pluricultural. La trama de estar con otros fractura entonces los discursos hegemónicos, reta a tejer puentes entre la vida cotidiana con múltiples epistemes y recrea su misma práctica para romper con la monotonía que muchas veces embarga a las instituciones educativas. No obstante, este horizonte necesariamente se vertebra de la emoción por lo que se realiza asociadamente; alli, las relaciones interpersonales dan fuerza a las ideas, sin imposiciones, pues es en el encuentro de pares donde se permite la confrontación y la propuesta (Martínez y Unda, 1998).

Ser red también es extenderse y tejer alto no solo desde lo distrital con la vinculación de diversos educadores, sino a nivel nacional, como sucede en los nudos Medellín y Tunja, donde el (la) maestro(a), que en algún momento inició un proceso, retoma lo abandonado. Para Roberto Esteban Hoyos, "lo que me tiene acá escribiendo y tratando de ser voz, son unos compañeros y compañeras que merecen todo mi respeto y admiración, quienes me han hecho creer que el camino hacia otra educación no es posible en solitario, como antes lo creía", quien más adelante gracias a la participación en el lberoamericano realizado se integraría a la Red Chisua, al recibir las puertas abiertas y los hilos dispuestos al tejido.

Los relatos que llegan del oriente antioqueño recuerdan que la motivación de participar en el siguiente Encuentro Iberoamericano a realizarse en México en 2017 afianza el tejido de amistad con Chisua en Bogotá, lo que gestaría junto a maestros como M. Borja, G. Casadiegos y R. Gómez la red en Medellín, comprendiendo que el (la) maestro(a) no está solo(a). La acogida en el Centro de Investigación y Estudios Pedagógicos (CIEP) de la Asociación Sindical de Educadores del municipio de Medellín (ASDEM), para vincular a otros educadores con su singularidad, permite que el colectivo crezca, se renueve, se alimente y se piense; creemos en la fuerza sindical, pero mucho más en el empuje que tiene el (la) maestro(a) y la escuela; guiado(a) por la importancia de la pedagogía crítica; sabemos que la criticidad sin alternativas no da esperanzas. Gracias a estas uniones hemos logrado participar en las Bienales de Infancias y Juventudes, en el Seminario Internacional "Redes de Conocimiento, Escuela e Interdisciplina", en publicaciones en revistas como Magisterio o Esfera, de la Universidad Distrital, o como árbitros evaluadores de productividad académica de distinta indole.

Seguir haciendo tejido requiere de esfuerzos y de política, pero sobre todo del poder microfísico que, al modo de Foucault (1992), cada uno puede hacer desde el aula, la charla y el diálogo con su colega, el padre de familia o el estudiante; esta es la mejor forma de creer que la unión que produce la red tiene sentido, por cuanto quienes estamos en ella confiamos en nuestra labor y saber, y en las micropolíticas que tienen lugar en las aulas y las calles. Educar, estar en colectivo y marchar nos convence de que vale la pena luchar por un camino de humanidad, pero que la única forma de hacer esto es pensando en ser otros - nosotros-.

En otro territorio de Colombia, los hilos llegarian a tejer, esta vez en las entrañas de Boyacá, con maestros(as) en formación y en ejercicio, que, en sus procesos de autoconstrucción y formación académica y personal, decidieron aunar sus esfuerzos en aras de repensar las infancias. Con el fin de mostrar el valor de niños y niñas como sujetos éticos, políticos y estéticos que merecen su papel protagónico en la sociedad, especialmente en el escenario educativo, se plantean rutas de investigación muy diversas que detonan apuestas y reflexiones para reconocer las concepciones sobre lo que son, las relaciones adultocéntricas y resignificar tanto el rol mediador en las aulas, como las dimensiones del currículo, la evaluación, los aprendizajes y la diversidad.

En ese devenir cimentado desde el semillero de investigación Hipatia del Grupo de Investigación Infancias y Expresiones (GIEX), adscrito a la Licenciatura en Educación Infantil de la Universidad Pedagógica y Tecnológica de Colombia (UPTC), surge la invitación 
de la Red Chisua a ser parte del colectivo de maestros(as) que en Tunja se da en 2019. Este tejido invita a compartir saberes y experiencias en torno a una educación que nos hermana por procesos críticos socioculturales del acontecimiento pedagógico en diferentes contextos de formación de niños, niñas, jóvenes y comunidades, y donde la diversidad de la red se arraigaría como una oportunidad de riqueza cultural y académica ${ }^{3}$. Este itinerario conlleva no solo a disertar alrededor de las diferencias sexuales, la interculturalidad, los derechos humanos, las prácticas populares emancipadoras para las infancias, las memorias históricas en territorios biodiversos, la educación en tiempos de covid-19, también, a afianzar afectos con el nudo Bogotá y fortalecer mayores apuestas con Minciencias que se reviertan en proyectos de innovación en el aula.

Si bien el nudo Chisua en Tunja se posiciona con la labor reflexiva e investigativa tanto de docentes universitarios como de colegios, la estructura organizativa y de gestión en su mayoría ha sido dinamizada desde su inicio por estudiantes docentes en formación de la uPTc de la Licenciatura en Educación Infantil, que abanderan el pensar en su contribución a las realidades actuales y movilizan discusiones colectivas entre el semillero Hipatia y la Red Chisua; estar en colectivo tributa entonces a su formación como jóvenes críticos investigadores.

\section{Cre-ser como maestros(as)}

El entrelazamiento de los hilos muestra que ser red es tejer de continuo y ello emociona transformaciones para seguir fortaleciendo el compromiso social más allá de intereses personales. La disposición a aprender en conjunto con otras personas y actuar movidos por ideales en busca de una sociedad mejor, halla en la producción escrita un aliado para gestar

3 Por ejemplo, en el Encuentro e intercambio de experiencias "Maestros y maestras de infancias: retos en sus procesos y prácticas de emancipación", en el cual se hace el lanzamiento oficial de la Red Chisua nodo Boyacá, en la UPTc. En este mismo evento, se socializa la serie audiovisual Colombia bio de Colciencias y los propósitos de la alianza de la Red Chisua para ser parte de las comunidades de aprendizaje. pensamiento y develar conocimientos críticos y propios de las pedagogías en los territorios. Hacer frente a los nudos propios del tejido, hace indispensable consolidar dinámicas comunicativas que siempre invitan a trenzar sin decaer.

En tal sentido, maestros(as) que se anudan en Chisua, se empoderan, afirman su identidad y enriquecen su formación y ejercicio profesional con acciones enmarcadas en seminarios, simposios, proyectos y producciones escritas, siendo la red una cuna de discernimiento, proposición e investigación colectiva; por eso aqui no hacen falta ideas ni ganas, hacen falta más maestros convencidos de que el trabajo en colectivo es un estilo de vida en el que crecemos para ser de otro modo posible. $Y$ es que quien se hace en la comunitariedad se impregna de la esperanza continua de resignificar la escuela, pues estar con el otro a partir del saber y el relacionamiento de su humanidad, facilita ser voz para el país que forjamos. Esa fue una realidad vista en la participación de Ana Brizet Ramírez Cabanzo como delegada al Comité Distrital de Formación Docente (CDFD) (2019), lo que para las redes se constituye en un hecho histórico que se aúna a los procesos de reconocimiento, fortalecimiento y dignificación de los (las) maestros(as) como profesionales e intelectuales que inciden en la construcción y puesta en marcha de la política educativa. ¡Mantener nuestro lugar es un desafío por el cual debemos seguir apostando!

En estos tiempos de incertidumbre, lo que mejor le puede pasar a un profesional de la educación es abrir su mente y saber que puede contar con un par para reinventarse como maestra/o "de a pie", desde esa necesidad de crear ante la continua inquietud intelectual. Quizás es así también como maestros(as) en constante búsqueda se nutren del ímpetu de la colectividad para conquistar otras maneras de educar y de felicidad, en medio de esa mochila que te atrapa de afectos, voces, saberes, posibilidades y retos para seguir soñando una escuela de puertas abiertas, constructora de paz. 


\section{Referencias}

Baigorri, A. (1995). Apuntes para una sociología del ruido. En $\checkmark$ Congreso Español de Sociología. Granada, España. https://www.eweb.unex.es/eweb/sociolog/BAIGORRI/papers/ruido2.pdf

De Tezanos, A. (2016). Formación de maestros: los conceptos articuladores del diseño curricular. Educación y Cultura, 113.

Escorcia, T. G. (2019). "Eina" el tejer y des-tejer de una maestra. Revista Educación y Ciudad, 2(37). https://doi. org/10.36737/01230425.v2.n37.2019.2156

Escorcia, T., Montero, V. y Ramírez A. (2008). Vivencias de una crónica expedicionaria. Revista Nodos y Nudos, 3(25), 103-105.

Foucault, M. (1992). Microfísica del poder. Editorial Piqueta.

Hernández, I. (2017, 1 de noviembre). Indígenas muiscas crearon la primera 'mochila bogotana' con tejidos ancestrales. RCNRadio.com. https://www.rcnradio.com/bogota/ indigenas-muiscas-crearon-la-primera-mochila-bogotana-tejidos-ancestrales

Martínez, M. (2005). La figura del maestro como sujeto político. El lugar de los colectivos y redes pedagógicas en su agenciamiento. Revista Nodos y Nudos, 2(19), 4-12.

Martínez, M. C. (2008). Redes pedagógicas: la constitución del maestro como sujeto político. Editorial Magisterio.

Martínez, A. y Unda, M. P. (1995). Redes pedagógicas: espacios múltiples y abiertos. Revista Nodos y Nudos, 1(1), 4-7. https://revistas.pedagogica.edu.co/index.php/NYN/ article/view/1205
Martínez, A. y Unda, M. P. (1998). De la insularidad de las innovaciones a las redes pedagógicas. Revista Nodos y Nudos, 1(5). https://revistas.pedagogica.edu.co/index.php/ NYN/issue/view/118

Ramírez-Cabanzo, A. (2016). La cartografía pedagógica: un lente para investigar las experiencias educativas. Revista Internacional Magisterio, 82, 48-52.

Ramírez-Cabanzo, A. (2018). Itinerarios que potencian al maestro como intelectual de la pedagogía. En Maestra Escuela. La investigación y el maestro como intelectual de la pedagogía (pp. 12-28). Red Chisua.

Ramírez-Cabanzo, A. B. (2019). Investigando igestamos cultura de paz! tIC-TAC-TEP. Magazín Aula Urbana, (113), 18. https://revistas.idep.edu.co/index.php/mau/article/ view/2069

Ramirez, A., Escorcia, T. y Salazar, C. (2006). Caminantes expedicionarios de la escuela. Revista Nodos y Nudos, 2(20), 65-73.

Segura, D., Chaparro, C., Molina, A. y Piragua, L. (2006). Las redes de maestros: un espacio de diálogo intercultural. Revista Nodos y Nudos, 2(20), 5-10.

Zuluaga, O. (1999). Pedagogía e historia: la historicidad de la pedagogía. La enseñanza, un objeto de saber. Siglo del Hombre Editores, Anthropos. 


\section{Diálogo del conocimiento}

Resalto la importancia que tiene para el magisterio redescubrirse en red, sobre lo cual emergen una serie de trazos que van tejiendo principios de comunitariedad, producción de saberes, hilos que se construyen en los encuentros, convertidos en pedagogias colectivas. De estos modos se configuran de otro modo los sujetos que, a su vez, le dan mayor sentido al trabajo en red.

Este artículo muestra cómo por medio de la praxis se van transformando la escuela y los(as) maestros(as) y se constituyen en un referente para quienes apuesten por los procesos de emancipación desde las instituciones escolares.

El proceso de constitución de la red Chisúa invita a su vez a otros colectivos y redes magisteriales a realizar ejercicios de memoria y reflexión sobre sus propios trayectos educativos y pedagógicos, a profundizar en sus redescubrimientos, siendo éste un gran aporte a los (las) lectores(as) que estén caminando en común.

\section{Juan Carlos Jaime Fajardo}

Secretaria de Educación del Distrito (SED), Centro de Estudios e Investigaciones Docentes (CEID) de la Asociación Distrital de Trabajadoras y Trabajadores de la Educación (ADE) 